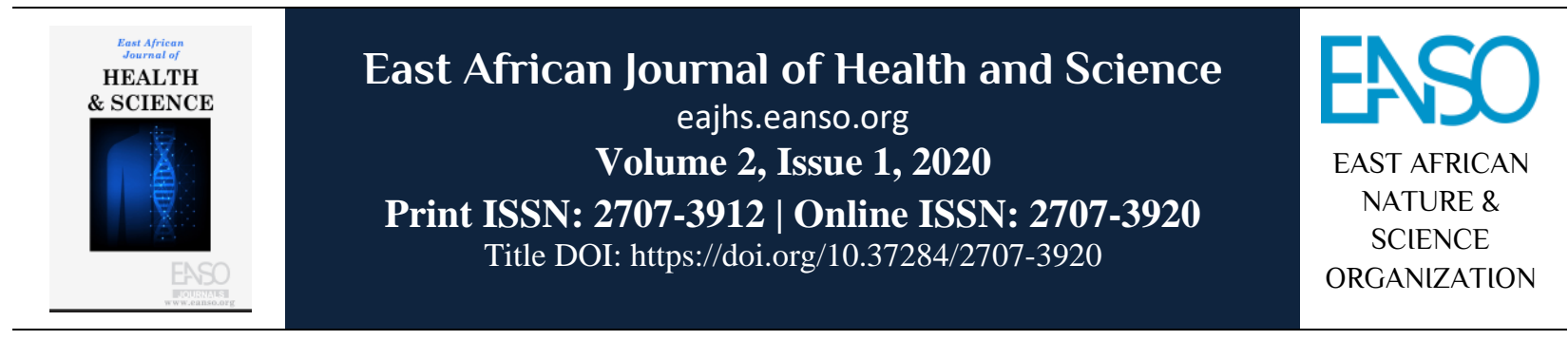

Original Article

\title{
Dynamics of Red Blood Cell Indices among Donor Samples in Kisii County, Western Kenya
}

\author{
Chrisphine Momanyi $i^{*}$, Dr. Stanslaus Kiilu Musyoki $i^{1} \&$ Dr. Benson Nyanchongi ${ }^{1}$ \\ ${ }^{1}$ Kisii University, P.O. Box 408-40200, Kisii Kenya. \\ *Author for correspondence email: chrisphinemomanyi@gmail.com.
}

Article DOI: https://doi.org/10.37284/eajhs.2.1.126

\author{
Article history: \\ Keywords: \\ Red Cell Indices, \\ Temperature, \\ Storage Time, \\ Donor Samples, \\ Kisii County, \\ Western Kenya.
}

Received: 26 Feb 2020

Accepted: 06 Mar 2020

Published: 28 Mar 2020

\begin{abstract}
Blood specimens are used to study the aetiology, diagnosis, treatment, prognosis, and prevention of blood diseases that includes research purposes. The primary health care worldwide calls for ideal systems that can provide accurate results but it is challenging to analyse the samples immediately. Thus, the primary objective of this study was to determine the changes in the red cell indices when stored at room temperatures. To accept such samples that have delayed after collections for some time as from zero (0) hours, at 6 hours, 12 hours, 24 hours and 48 hours requires testing and confirming the results validations. Therefore, this research analysed samples of blood to validate the results after storage at room temperature in different hours within 48 hours of storage at room temperature. Samples collected from donors aged 16-65 years at Kisii Teaching and Referral Hospital in Kisii County, Western Kenya were tested in this study. The technique of Flow cytometry was used to analyse results of blood obtained through Venepuncture procedure from donors and placed in $4 \mathrm{ml}$ Ethylene Diamine Tetra Acetic (EDTA) Vacutainer tubes of standardised anticoagulant ratio. A cross-sectional study with laboratory experiment was employed to analyse the data between the month of April and August 2018. Percentile male and female blood samples were analysed at $48 \%$ and 52\% respectively. The analytes of obtained were used to determine the two red blood cell parameters in controlled room temperature within 48 hours on Packed Cell Volume (PCV) and Total Red Cell counts. Statistical analysis with computerized applications package (SPSS, version 21.0) was used to determine the changes that occurred during the study with repeated Analysis of Variation (ANOVA). Comparative mean values were calculated for each blood samples. The results were insignificant at sixth and twelfth hours of storage for most
\end{abstract}


indices except from the RBC total counts, which had a deviation between 6-48 hours. In conclusion blood sample analysis is safe for tests results up 12 hours of storage at room temperature when not tested immediately after collection. This study recommends further finds for Reticulocytes Production Index to assess bone marrow activities.

\section{APA CITATION}

Momanyi, C., Musyoki, S., \& Nyanchongi, B. (2020). Dynamics of Red Blood Cell Indices among Donor Samples in Kisii County, Western Kenya. East African Journal of Health and Science, 2(1), 9-14. https://doi.org/10.37284/eajhs.2.1.126

\section{CHICAGO CITATION}

Momanyi, Chrisphine, Stanslaus Musyoki, and Benson Nyanchongi. 2020. "Dynamics of Red Blood Cell Indices Among Donor Samples in Kisii County, Western Kenya". East African Journal of Health and Science 2 (1), 9-14. https://doi.org/10.37284/eajhs.2.1.126.

\section{HARVARD CITATION}

Momanyi, C., Musyoki, S. and Nyanchongi, B. (2020) "Dynamics of Red Blood Cell Indices among Donor Samples in Kisii County, Western Kenya", East African Journal of Health and Science, 2(1), pp. 9-14. doi: 10.37284/eajhs.2.1.126.

\section{IEEE CITATION}

C. Momanyi, S. Musyoki, and B. Nyanchongi, "Dynamics of Red Blood Cell Indices among Donor Samples in Kisii County, Western Kenya", EAJHS, vol. 2, no. 1, pp. 9-14, Mar. 2020.

\section{MLA CITATION}

Momanyi, Chrisphine, Stanslaus Musyoki, and Benson Nyanchongi. "Dynamics of Red Blood Cell Indices Among Donor Samples in Kisii County, Western Kenya". East African Journal of Health and Science, Vol. 2, no. 1, Mar. 2020, pp. 9-14, doi:10.37284/eajhs.2.1.126.

\section{INTRODUCTION}

Blood consist of cellular and fluid matrix that creates an internal environment to bath as well protects the body against foreign pathogens. The cellular component of blood includes the three cells namely; erythrocytes, leukocytes and thrombocytes. Sample ageing can cause alteration of certain cell characteristics leading to changes in cellular variables. It's evidenced that the lifespan of the red blood cell is an influence in haemoglobin variations and the cell membrane structural degradations if tested at different timing after collection and can be used for the diagnosis of diabetes in human especially adult haemoglobin (Cohen \& Franco, 2016). These cellular components of blood are suspended in the fluid part of blood and their flow to specific body parts depends on the peripheral stress and the steady balance in circulation. The red blood cells (erythrocytes) are responsible for respiration processes and lack of this component either due to low production or premature destruction causes anaemia (Cascio \& DeLoughery, 2017). This condition is the major cause of high mortality rates among maternal patients in the third world countries Kenya being one of these countries. Accurate and reliable diagnosis using the red blood cell indices improves the quality of life (Vogelaar et al., 2002). Hence testing blood is a confirmatory indicator for human health life or otherwise the determinant of human health status. Nevertheless, there are conditions that call for delayed tests results to be obtained like the equipment capacity as well as the workforce. Delayed testing time must be documented to confirm the results output to reflect true findings that are reliable and reproducible in any laboratory hence the objectives of this study at Kisii Teaching and Referral Hospital.

Red blood cell (RBC) indices are part of the complete blood count test but any qualitative and quantitative changes that are observed in the red blood cell parameters are important diagnostic and prognostic indicators of various pathological processes of a disease like anaemia. Their haematological parameters that can be used to diagnose conditions like polycythaemia Vera and other blood disorders (Salisbury et al., 2012). The red blood cell indices include Mean Cell Volume 
(MCV) which indicates the average red blood cell size; Haemoglobin amount per a red blood cell $(\mathrm{MCH})$; the amount of Haemoglobin relative to the size of the cell per red blood cell (MCHC); the amount of haemoglobin concentration per a red cell (HB) are more often used to access and monitor the efficacy of drugs. However, this research did the variations of the Red Blood Cell (RBC) counts and Packed Cell Volume (PCV) to describe cell maturation as well as programmed cell death in absolute counts. The two indictors had an indirect understanding of the processes occurring in the cytoplasmic membrane of red blood cells and often than not these laboratory parameters are frequently overlooked in clinical practice but they provide assistance in establishing a diagnosis in anaemic patients (Cavaliere, 2004). These indicators show not only the degree of erythrocyte damage but the red cell size variation used to indicate systematic iron status (Alexander et al., 2002). The specimens that are tested to provide investigation for a patient's condition ideally must be tested immediately after collection for quality and accuracy of results which are reliable as well as reproducible (Vogelaar et al., 2002).

The current techniques applied in the field of medical haematology for blood analysis are conducted by means of automatic haematological analyser. Flow cytometry is the best technology used for diagnosis, monitoring and categorization of all blood parameters in given conditions to be able to detect any changes, international unit or as a percentage of whole blood (\%) (Lewis et al., 2008). The volume of red cell reported as a proportion of the total sum of red cell in regard to the total volume of the sample analysed will provide the analytic value of percentile representations of the normal cell that determines the packed cell volume to provide the clinical manifestations of anaemia and other conditions of blood in relation to the red cell. A study done on alteration of red cell indices at different time and temperatures for patients with different conditions like leukaemia and Polycythaemia Vera have reported different outcomes using this sensitive machine (Chesney et al., 2011). The equipment uses vacuum systems with KI-EDTA anticoagulant blood, reagents package of diluents, lysing solution, differentiation reagent and caustic cleaner. This technology was used in the study carried with donor samples obtained at Kisii Teaching and Referral Hospital for a period of four months.

There are several methods that can be applied for the cell count ranging from manual to automations. In this research, automation methodology was used with improved flow cytometry to have the desired results with an average of 10 minutes and provides additional modes of quality controls to analyse blood specimens. An instrument used was a Coulter Counter S model, which employed the principle of electric impedance for all the analytes of blood components in performing cell counts. Most of the automated machines give the values and the ranges making it easier to interpret results with others showing red-flagging where there are anomalies for both white cell count, red cell count, platelet count, haemoglobin, haematocrit, $\mathrm{MCV}, \mathrm{MCH}$, and MCHC. Newer machines, capable of calculating RDW or red cell morphology index are available and in use. However this was in relation with previously researched results (Sarma, 1990). This study was able to identify and filter the two indicators from the total tested and run results showing both the cellular components of blood and blood products.

\section{MATERIALS AND METHODS}

\section{Site of Study}

The study was conducted at Kisii Teaching and Referral Hospital in Kisii County, Western Kenya. Kisii has a satellite transfusion centre which was used as the centre of getting samples. The facility was established in 1916 as a Centre treating wounded soldiers during World War I in Gusii land, Western Kenya where blood samples collected from donors. This hospital is strategically located to serve broad spectrum as a referral for the Western region, Kenya. It resolves through preventive, curative, rehabilitative and research institution with a bed capacity of 700. Kisii county referral hospital has the capacity that has been established to serve more both in research and in treatment. More facilities that are peripheral receive services in this institution having 142 public and private health centres. Approximately Kisii county has a population of 1.4 million within a population density of $874 / \mathrm{km}^{2}$. The institution is accessible 
with a $5 \mathrm{~km}$ distance recommended to serve patients at different peripheral facilities.

\section{Study Design}

A longitudinal study design was used to assess the dynamics of the red blood cell indices within 48 hours when stored a constant of room temperature. An average of four (4) blood samples were collected from donors for this study and tested for their comparative dynamics at intervals from zero (0) hours, at 6 hours, 12 hours, 24 hours and 48 hours for twenty-five working days.

The study tested 100 blood samples collected from both male and female donors aged between 16-65 years. These participants were voluntarily recruited during blood donations to save life at Kisii Teaching and Referral Hospital. World Health Organization guideline was used to assess donor suitability for blood donation, this SOP was developed and adopted to assist blood transfusion services in countries. The document was established to strengthen national systems for the selection of suitable blood donors adopted by the year 2011. This is a vital service to ensure that patients access safe blood and blood products for an effective health system nationally. Both male and female participants were recruited using donor consent and screening methods accepted worldwide. The calculated sample size was determined according to the Cochran's general formula and adjusted to 100 samples that were processed during this study with a gender distribution of 48 males and 52 females between April and August 2018. Adjustment of the formulae was applied to determine the actual proportions of donor samples at Kisii County hospital blood transfusion department. The sample size was adjusted to represent Kisii county proportion of the study population for donors at KTRH.

\section{Laboratory Analysis}

Flow cytometry was used to analyse whole blood collected aseptically by Venepunctures procedure using coulter counter equipment. The blood samples were collected into $4 \mathrm{ml}$ Ethylene Diamine Tetra Acetic (EDTA) Vacutainer tubes of known volume to anticoagulant ratio. A standard coulter machine was used to analyse for their dynamics for the red blood cell indices. The analyses were done at baseline i.e. immediately after blood donation $(0$ hours) and subsequently after 6 hours, 12 hours, 24 hours and then after 48 hours. This is a replica of five tests done of the same samples of blood from the donors. Statistical analysis with computerized applications package (SPSS, version 21.0) was used to determine and evaluate the changes of red blood cell indices at room temperature with time.

\section{Ethical Considerations in the Study}

Ethical clearance for this study was obtained with approval by the Scientific and Ethics Review Committee of Baraton University of East Africa (RE: UEAB/04/10/2016). Research permit was sought from the National Commission for Science, Technology and Innovations (NACOSTI/P/17/42307/15886). Permissions were also sought from Kisii University and KTRH. All procedures were in accordance with the ethical standards for data collection, written informed consent was sought while privacy and confidentiality were maintained throughout the study. The research assistants were well trained on the written consent form before they administered to donors to ensure all research detailed requirements were met to standardize the processes.

\section{RESULTS AND DISCUSSIONS}

The study evaluated the changes of red blood cell indices whereby two indicators were extensive monitor for any changes within 48 hours of storage at room temperature. Red Blood Cell count and packed cell volume over time in Kisii County evaluates the reticulocyte reproduction index with time. The demographic characteristics of the study participant were hundred (100) participants of which $48 \%$ were male and $52 \%$ were female with a mean age of 38 years. The red blood cell indices under study: RBC total count and packed cell volume were found to have variations at different storage time under room temperature. The study observed that the changes of red blood cells were the same for the first 6 hours of storage as the baseline, however, the subsequent results demonstrated significant changes in the RBC counts. The study, therefore demonstrate that total red blood cells can be analysed when the sample has been stored at room temperature for 6 hours but 
East African Journal of Health and Science, Volume 2, Issue 1, 2020

Article DOI: https://doi.org/10.37284/eajhs.2.1.126

should not be used beyond 12 hours as shown in

Table 1 .

Table 1: Mean Change of Red Blood Cell Counts over Time at Room Temperature

\begin{tabular}{llllll}
\hline TIME & $\mathbf{0}$ & $\mathbf{6}$ & $\mathbf{1 2}$ & $\mathbf{2 4}$ & $\mathbf{4 8}$ \\
\hline 6 & $0(4.20,4.20)$ & N/A & N/A & N/A & N/A \\
12 & $0.3(4.20,4.50)$ & $0.4(4.20,4.50)$ & N/A & N/A & N/A \\
24 & $-1.1(4.20,3.10)$ & $-1.9(4.20,3.10)$ & $-1.4(4.50,3.10)$ & N/A & N/A \\
48 & $-1.0(4.20,3.20)$ & $-1.0(4.20,3.20)$ & $-1.3(4.50,3.20)$ & $-0.1(3.10,3.20)$ & N/A \\
\hline
\end{tabular}

On the other hand, the packed cell volume did not show any significant changes for the entire testing period of time up to 48 hours. This study, therefore, showed an insignificant change as tabulated as shown in Table 2.

Table 2: Mean Change of PCV over Time at Room Temperature

\begin{tabular}{llllll}
\hline TIME & $\mathbf{0}$ & $\mathbf{6}$ & $\mathbf{1 2}$ & $\mathbf{2 4}$ & $\mathbf{4 8}$ \\
\hline 6 & $0.4(40.2,39.8)$ & $N / A$ & $N / A$ & $N / A$ & $N / A$ \\
12 & $0.4(40.2,39.8)$ & $0.4(39.8,39.4)$ & $N / A$ & $N / A$ & $N / A$ \\
24 & $0.4(40.2,39.8)$ & $0.4(39.8,39.4)$ & $0.4(39.4,39.0)$ & $N / A$ & $N / A$ \\
48 & $0.4(40.2,39.8)$ & $0.4(39.8,39.4)$ & $0.4(39.4,39.0)$ & $0.3(39.0,38.7)$ & $N / A$ \\
\hline
\end{tabular}

\section{CONCLUSIONS AND} RECOMMENDATIONS

The finding of this study shows that delay in sample analysis for total red blood cells counts shall be reliable and reproducible for valid results if only tested within 6 hours after blood collection. This is evidenced when the same donor sampled blood was tested at $12^{\text {th }}$ hour, $24^{\text {th }}$ hour and then at the $48^{\text {th }}$ hour of storage had changes in their absolute counts. Red cell counts increased in the first 6 hours because of natural programmed cell maturation while in circulation describing the rate of reticulocyte maturation rates (Koury et al., 2005) But if tested when stored for more than 6 hours the total counts of the red blood cell reduces drastically because of apoptosis processes (Elmore, 2007).

This research also analysed the possible changes of packed red blood cell volume, for the entire testing period for each sampled blood from donors. The study shows that the packed cell volume can be used at any time within 48 hours of storage at room temperature and the results are as good as the initials. However, this indicator alone may not be possible to make conclusions in case of patient diagnosis but the best during the assessment of the cell volume ratios in comparison with plasma levels(Pidcoke et al., 2015). The study therefore, recommends that delay of analysis of blood samples for any unforeseen circumstances e.g. machine breakups, power outages delay of referral samples can be used with caution if specific parameters are used to give a desired result for diagnosis or research. The use of PCV results to make a diagnosis and prognosis is valid for 48 hours of storage at room temperatures. But the red blood cells can be used within the first 6 hours of collection and stored at room temperatures

\section{ACKNOWLEDGEMENT}

Gratitude is expressed to Kisii University, School of Health science and Kisii Teaching and Referral Hospital Laboratory staff in the Research Department for their support in data collection. Special thanks also to any other person that may have contributed in one way or another towards the success of this study. 


\section{REFERENCES}

Alexander, H. D., Sherlock, J. P., \& Bharucha, C. (2000). Red cell indices as predictors of iron depletion in blood donors. Clinical and Laboratory https://doi.org/10.1046/j.13652257.2000.00323.x

Cavaliere, T. A. (2004). Red blood cell indices: Implications for practice. Newborn and Infant Nursing

Reviews. https://doi.org/10.1053/j.nainr.2004.09.006

Cascio, M. J., \& DeLoughery, T. G. (2017). Anaemia: Evaluation and Diagnostic Tests. Medical Clinics of North America. https://doi.org/10.1016/j.mcna.2016.09.003

Chesney, A., Good, D., \& Reis, M. (2011). Clinical Utility of Flow Cytometry in the Study of Erythropoiesis and Nonclonal Red Cell Disorders. Methods in Cell Biology. https://doi.org/10.1016/B978-0-12-3854933.00013-9

Cohen, R. M., \& Franco, R. S. (2016). Can red blood cell indices act as surrogate markers for discordance between haemoglobin A1c and fasting blood glucose? Clinical Chemistry. https://doi.org/10.1373/clinchem.2016.264705

Lewis, G. K., Lewis, G. K., \& Olbricht, W. (2008). Cost-effective broad-band electrical impedance spectroscopy measurement circuit and signal analysis for piezo-materials and ultrasound transducers. Measurement Science and Technology. $\quad$ https://doi.org/10.1088/09570233/19/10/105102

Lim, H., Lee, Y.-J., Nam, J.-H., Chung, S., \& Shin, S. (2010). Temperature-dependent threshold shear stress of red blood cell aggregation. Journal of Biomechanics. https://doi.org/10.1016/j.jbiomech.2009.09.03 1

Philipsen, J. P., \& Madsen, K. V. (2015). Hypo- and hypernatremia results in inaccurate erythrocyte mean corpuscular volume measurement in vitro, when using Sysmex XE 2100. Scandinavian Journal of Clinical and
Laboratory Investigation. https://doi.org/10.3109/00365513.2015.10625 34

Salisbury, A. C., Amin, A. P., Reid, K. J., Wang, T. Y., Alexander, K. P., Chan, P. S., ... Kosiborod, M. (2012). Red blood cell indices and development of hospital-acquired anaemia during acute myocardial infarction. American Journal of Cardiology. https://doi.org/10.1016/j.amjcard.2011.11.045

Sarma, P. R. (1990). Red Cell Indices. Clinical Methods: The History, Physical, and Laboratory Examinations.

Stanley L Schrier, M. (2018). Macrocytosis/Macrocytic anaemia. UpToDate.

Vogelaar, S. A., Posthuma, D., Boomsma, D., \& Kluft, C. (2002). Blood sample stability at room temperature for counting red and white blood cells and platelets. Vascul. Pharmacol, 39(3), 123-125. Retrieved from http://www.ncbi.nlm.nih.gov/pubmed/126169 78 